\title{
Nano-zinc oxide damages spatial cognition capability via over-enhanced long-term potentiation in hippocampus of Wistar rats
}

This article was published in the following Dove Press journal:

International Journal of Nanomedicine

8 July 2011

Number of times this article has been viewed

\section{Dadong Han' \\ Yutao Tian ${ }^{2}$ \\ Tao Zhang ${ }^{2}$ \\ Guogang Ren ${ }^{3}$ \\ Zhuo Yang'}

'School of Medicine, The Key Laboratory of Bioactive Materials, Ministry of Education, ${ }^{2}$ College of Life Science, Nankai University, Tianjin, China; ${ }^{3}$ Science and Technology Research Institute, University of Hertfordshire, Hatfield, Hertfordshire, UK
Correspondence: Zhuo Yang School of Medicine, Nankai University, Tianjin 30007I, China Tel +8622 23504364 Fax +86 2223502554 Email zhuoyang@nankai.edu.cn

\begin{abstract}
This study focused on the effects of zinc oxide nanoparticles (nano- $\mathrm{ZnO}$ ) on spatial learning and memory and synaptic plasticity in the hippocampus of young rats, and tried to interpret the underlying mechanism. Rats were randomly divided into four groups. Nano-ZnO and phosphate-buffered saline were administered in 4-week-old rats for 8 weeks. Subsequently, performance in Morris water maze (MWM) was determined, and then long-term potentiation (LTP) and depotentiation were measured in the perforant pathway to dentate gyrus (DG) in anesthetized rats. The data showed that, (1) in MWM, the escape latency was prolonged in the nano-ZnO group and, (2) LTP was significantly enhanced in the nano-ZnO group, while depotentiation was barely influenced in the DG region of the nano- $\mathrm{ZnO}$ group. This bidirectional effect on long-term synaptic plasticity broke the balance between stability and flexibility of cognition. The spatial learning and memory ability was attenuated by the alteration of synaptic plasticity in nano-ZnO-treated rats.
\end{abstract}

Keywords: zinc oxide nanoparticles, synaptic plasticity, long-term potentiation, depotentiation, spatial learning, memory

\section{Introduction}

Zinc oxide nanoparticles (nano- $\mathrm{ZnO}$ ) are now widely applied in many products such as toothpaste, beauty agents, sunscreens, textiles, wall paints, and other building materials. Many properties of nanoparticles, such as surface and interface effects, ${ }^{1}$ quantum size effect, ${ }^{2}$ photocatalytic properties, ${ }^{3}$ and phonon properties, ${ }^{4}$ have been investigated. In humans, environmental exposure to nano- $\mathrm{ZnO}$ has shown that it stayed in the stratum corneum and accumulated in skin folds and/or hair follicle roots of the skin. ${ }^{5}$ Also, exposure to low concentrations of nano- $\mathrm{ZnO}$ indicates a genotoxic potential mediated by lipid peroxidation and oxidative stress in epidermal cells. ${ }^{6}$ Similarly, the liver, spleen, heart, pancreas, and bone were the target organs for 20- and 120-nm $\mathrm{ZnO}$ exposure. ${ }^{7}$ However, nano- $\mathrm{ZnO}$ was selectively toxic toward potential disease-causing cells, and has been regarded as a possible treatment for cancer and/ or autoimmune diseases. ${ }^{8}$

With regard to nervous tissue, data have shown that Neuro-2A cells exposed to nano- $\mathrm{ZnO}$ at doses $>100 \mu \mathrm{g} / \mathrm{mL}$ in vitro become abnormal in size, and display cellular shrinkage and detachment from the surface of flasks. Flow cytometer tests show that apoptosis occurs in mammalian neuro-2A cells when exposed to nano-ZnO. ${ }^{9}$ Human neural cells and fibroblasts undergo apoptosis and necrosis ${ }^{10}$ when exposed to nano-ZnO. Recent experimental studies of acutely isolated rat hippocampal $\mathrm{CA}_{3}$ pyramidal neurons show that exposure to nano- $\mathrm{ZnO}$ results in increases in amplitude 
of sodium current $\left(\mathrm{I}_{\mathrm{Na}}\right)$, delayed rectifier potassium current $\left(\mathrm{I}_{\mathrm{K}}\right)$, and excitability of neurons. The results suggest that these mechanisms may contribute to cell apoptosis. ${ }^{11,12}$ Nano-ZnO increases neuronal excitability by enhancement of $\mathrm{Na}^{+}$influx leading to the accumulation of intracellular $\mathrm{Ca}^{2+}$. Furthermore, concentration of intracellular $\mathrm{Ca}^{2+}$ is a crucial and essential source of long-term potentiation (LTP) and long-term depotentiation (LTD) in both inducing and maintaining phases. ${ }^{8}$ Such effects manifest dose dependency but no size-dependent toxicity. ${ }^{13}$

Although recent epidemiological studies demonstrated a correlation between exposure to fine particulate matter in industrial applications and an increased incidence of morbidity, the mechanisms behind this correlation remain largely unknown. Indeed, few studies of nano- $\mathrm{ZnO}$ properties have been concerned with actions in the nervous system and effects on cognition. Given that nano- $\mathrm{ZnO}$ is widely used in fields which are closely related to the human living environment, whether long exposure to nanoparticles could have a damaging impact on cognitive function is unclear. Therefore, based on the need for biological safety, this study focused on the effects of nano- $\mathrm{ZnO}$ on spatial learning and memory and synaptic plasticity in the hippocampus of the immature nervous system in Wistar rats, and attempted to interpret the underlying mechanism.

\section{Materials and methods}

\section{Animals and treatment}

Wistar rats (postnatal days 28) were placed under environmentally controlled conditions (0700-1900 hours light/dark cycle; $20^{\circ} \mathrm{C}-24^{\circ} \mathrm{C}$ ) and permitted free access to food and water throughout the experiment. The procedures involving the animals and their care complied with national and international rules and policies. Experiments were designed to minimize the number of animals used and their suffering.

A total of 32 rats was randomly divided into four groups: (1) nano-ZnO-treated group for Morris water maze (MWM) test $(\mathrm{n}=8),(2)$ nano-ZnO-treated group for electrophysiological experiment $(n=8)$, (3) normal control group for MWM $(n=8),(4)$ normal control group for electrophysiological experiment $(n=8)$. Rats were intraperitoneally injected with nano-ZnO (4 mg/kg, $4 \mathrm{mg} / \mathrm{mL}$, biweekly [biw] $)^{14}$ and the same volume of phosphate-buffered saline (PBS) (biw) from the fourth to the twelfth week after birth, respectively.

In the present study, intraperitoneal administration instead of intracerebral or intraventricular injection was applied as delivery pathway. The main reason was to avoid the damage of surgical operation. Whether nano-ZnO can cross the blood-brain barrier (BBB) has not been determined. However, other studies on the effects of nanoparticles, have reported that other kinds of nanoparticles (like gold nanoparticles) injected into the tail vein of healthy mice show a biodistribution in the brain, and this has been characterized in detail. ${ }^{15}$ One other study exposing rats to $\mathrm{ZnO}$ given daily $(100 \mathrm{mg})$ via a gastric tube, showed morphological and histochemical changes in the brains of rats. ${ }^{16}$ Based on these data, we assumed that nano- $\mathrm{ZnO}$ given intraperitoneally can cross the BBB and have influence on the brain.

\section{Nano- $\mathrm{ZnO}$ and suspension preparation}

In this research, the nano- $\mathrm{ZnO}$ was analyzed and provided by the Research Institute of Science and Technology (RSTI) University of Hertfordshire, Hampshire, UK. The morphology of the nano- $\mathrm{ZnO}$ was investigated through transmission electron microscopy (TEM) (Tecnai G2 20S-TWIN, FEI Co, Portland, OR). The TEM images showed that nano-ZnO were within the sizes 20-80 nm (as shown in Figure 1). Suspension of nano-ZnO was prepared in PBS (1 mg nano$\mathrm{ZnO}$ in $1 \mathrm{~mL} \mathrm{PBS}$ ) at $25^{\circ} \mathrm{C}$. Because nano- $\mathrm{ZnO}$ was barely dissolved in water, ultrasound was applied for 1 hour at a power of $3 \mathrm{~W}$ to ensure nanoparticle dispersion and to prevent nano- $\mathrm{ZnO}$ deagglomeration and reagglomeration. ${ }^{17}$ The resulting suspension was then immediately pipetted into a glass container and administrated intraperitoneally to the rats.

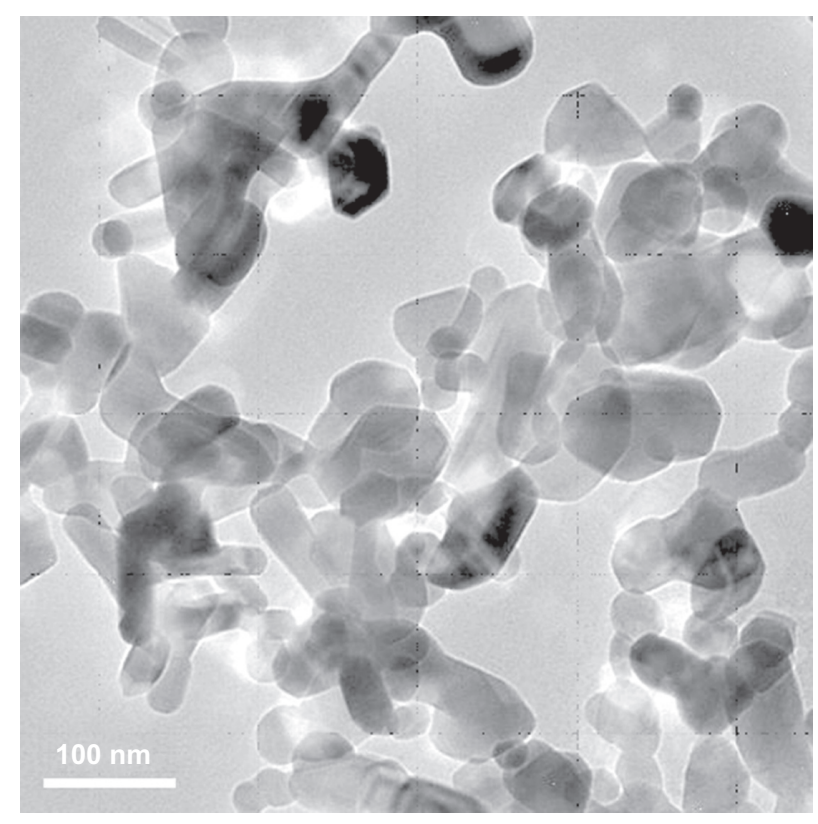

Figure I Transmission electron microscopy image of nanoscaled $\mathrm{ZnO}$ particles. 


\section{MWM}

After 8-week intraperitoneal administration, MWM was performed. MWM is an established test of spatial learning and of reference memory. ${ }^{18}$ The maze was placed in a room with soft lighting. All light fixtures in the room were covered with white sheets to reduce the brightness of the lights and eliminate their reflection in the water. All experiments were performed at 0800 and 1800 hours. The MWM was made of a circular tub (height $60 \mathrm{~cm}$, diameter $150 \mathrm{~cm}$ ), and the water was heated to $23.5^{\circ} \mathrm{C}$ using a built-in heater. The pool was divided into four quadrants: northeast (NE), northwest (NW), southeast (SE), and southwest (SW). A circular platform (diameter $10 \mathrm{~cm}$ ) was placed $1.5 \mathrm{~cm}$ below the surface of the water in the middle of the NE quadrant of the pool, and visual cues were placed on the walls surrounding the pool. Rats had to find the location of the hidden platform to escape from the water. ${ }^{19,20}$ Rats received two trials a day from four start positions with a 5-minute intertrial interval during which animals rested in their home cage. Rats were put in the pool facing the sidewall and were allowed 60 seconds to locate the platform. Rats that failed to locate the platform within 60 seconds were guided by hand to the platform. All rats were allowed to sit on the platform for 10 seconds before being removed from the pool. ${ }^{21}$ During the first 5 days of training (acquisition phase), the hidden platform was consistently located in the NE quadrant.

On day 6 (retention phase), a probe trial was carried out. The probe trial was a 60 -second test, but there was no platform in the pool. The time that each rat spent in each quadrant in which the platform had been located during training was recorded.

On days 7 and 8 (reacquisition phase), reverse platform training was instituted, and for this, the hidden platform was moved from the NE quadrant to the center of the SW quadrant ( $25 \mathrm{~cm}$ from the pool wall) without changing any distal visual cues. Reversal trials were administered as described in the acquisition phase, except that the platform was moved to the middle of the SW (opposite) quadrant.

Data were collected with a TopScan (Clever Sys Inc, Reston, VA) system, which records MWM performance automatically using a digital video camera mounted directly above the pool. Data were then automatically scored via the TopScan computer software package.

\section{LTP and depotentiation recording}

On day 9 , the rats were anesthetized with urethane $(1.2 \mathrm{~g} / \mathrm{kg}$, intraperitoneally) and mounted on a stereotaxic frame (SR-6N; Narishige, Japan). Small holes were drilled in the skull to allow insertion of electrodes into the brain. The stereotaxic coordinates were derived from Paxinos and Watson. ${ }^{22}$ A concentric bipolar stainless steel stimulating electrode with a tip separation of $0.5 \mathrm{~mm}$ was placed into the perforant pathway (PP) (coordinates: $8.0 \mathrm{~mm}$ posterior to bregma, $4.4 \mathrm{~mm}$ lateral to the midline, $2.8-3.8 \mathrm{~mm}$ ventral from the cortical surface). A monopolar extracellular stainless steel recording electrode, $0.5 \mathrm{~mm}$ in diameter, was lowered into the dentate gyrus (DG) region (coordinates: $4.2 \mathrm{~mm}$ anterior to bregma, $2.5 \mathrm{~mm}$ lateral to the midline, $3.0-3.7 \mathrm{~mm}$ ventral from the cortical surface).

After positioning the electrodes, the rats were left for a minimum period of 30 minutes for stability of baseline recordings before starting the experiment. Evoked field responses were recorded (Neurolog NL 104, NL 125, PowerLab/8S; AD Instruments, Sydney, Australia). The slopes of field excitatory postsynaptic potential (fEPSP) were measured as the maximal slope between the $20 \%-80 \%$ points obtained on the first positive deflection of the potential.

For induction of LTP in the DG by stimulation of the $\mathrm{PP}$, a probe stimulus was chosen at an intensity sufficient to produce a field response approximately $50 \%$ of spike threshold (ST). Baseline responses (1 per minute) were recorded for 20 minutes followed by induced theta burst stimulation (TBS), consisting of four theta epochs delivered at $0.1 \mathrm{~Hz}$. Each epoch consisted of 20 trains of 4 pulses (at $200 \mathrm{~Hz}$ ) delivered at $5 \mathrm{~Hz}$ at the same stimulus intensity as the baseline pulse. ${ }^{23}$ High-frequency stimulation (HFS) lasted 40 seconds in total. Following HFS, single-pulse recording resumed for 90 minutes. ${ }^{24}$

After LTP was recorded, the evoked responses of the last 20 minutes were normalized and used for the baseline of depotentiation (1 per minute), and then low frequency stimulation (LFS) containing two series of low-frequency stimulations ( $1 \mathrm{~Hz}, 10$ minutes, total LFS 20 minutes) was applied. Following LFS, single-pulse recording resumed for 90 minutes. All operations were performed in the same time period.

\section{Statistical analysis}

All data were analyzed using version 16 of the Statistical Package for Social Sciences (SPSS) (IBM, Somers, NY).

The baseline fEPSP (excitatory postsynaptic potential) data were obtained by averaging the response of stimulating PP, and analyzed offline with ES500 Scope and Chart Software (eDaq, Sydney, Australia). Statistical significance was estimated using analysis of variance (ANOVA) with repeated measures. The probability level interpreted as statistically significant was $P<0.05$. 
The data in each trial of MWM were combined to calculate the mean for each training session. Data from the acquisition phase were analyzed by repeated-measures ANOVA (group/day) and one-way ANOVA, data from the retention phase were analyzed by one-way ANOVA, ${ }^{25}$ and data from the reacquisition phase were analyzed by repeatedmeasures ANOVA (group/day) and one-way ANOVA. Results were expressed as the mean \pm standard error of the mean. The probability level interpreted as statistically significant was $P<0.05$.

\section{Results}

\section{Morris water maze}

Spatial cognition capability was evaluated in rats using the MWM test.

\section{Acquisition performance}

The learning curves for MWM are shown in Figure 2. All rats showed a progressive improvement in the escape latency over time in a trial-dependent manner. This suggested that substantial learning had occurred in this period in both nano$\mathrm{ZnO}$ and control groups. During the first two trials of training, no significant differences were observed between the nano$\mathrm{ZnO}$ and control groups (trial 1, $69.17 \pm 9.55$ seconds and $48.88 \pm 9.83$ seconds; trial 2, $28.25 \pm 4.14$ seconds and $21.25 \pm$ 5.71 seconds, $P>0.05$ ). Conversely, the escape latencies were significantly higher in rats of the nano-ZnO-treated group than that of control group from the third to tenth trials $(P<0.05$, $P<0.01)$. In the acquisition phase, statistical significances were observed between the nano- $\mathrm{ZnO}$ and control groups $(P<0.01$, repeated-measures ANOVA, Figure 2A).

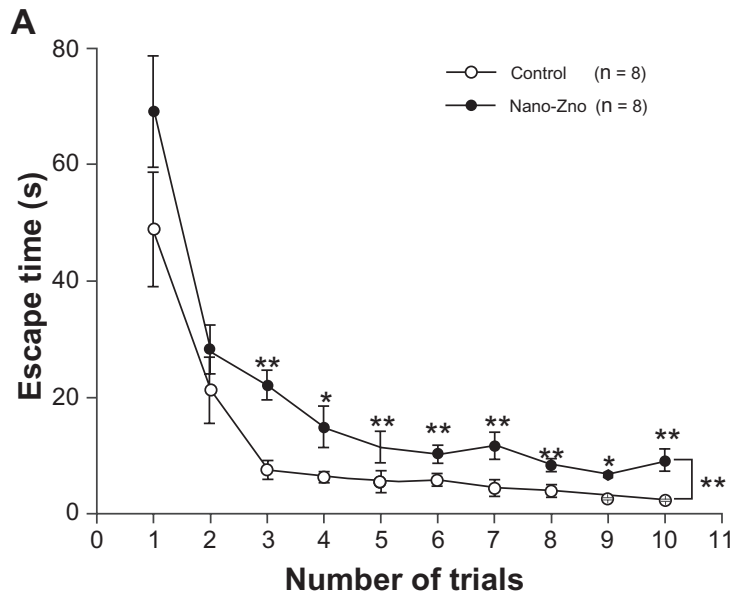

The same tendency was revealed in the data of the percentage of escape latency of temporal distribution in the target quadrant before the probe trial. Each performance of a trial was much worse in the nano-ZnO-treated group than that of control $(P<0.05, P<0.01$, Figure $2 \mathrm{~B})$. These data indicate that the learning performance of the nano-ZnOtreated group was weakened by nano- $\mathrm{ZnO}$ compared with that of the control group.

\section{Retention performance}

On day 6, rats of the nano-ZnO-treated group spent significantly shorter times in the SW target quadrant than those of the control group (control, $55.81 \% \pm 3.05 \%$; nano-ZnO-treated group, $36.28 \% \pm 5.37 \%, P<0.05$ ), as shown in Figure 3A. The performance on the number of crossing fictitious platform times in rats of the nano-ZnO-treated group was not as good as that of the control (control, $6.67 \pm 0.80$ seconds; nano-ZnO-treated group, $2.83 \pm 0.79$ seconds, $P<0.05$, Figure $3 \mathrm{~B})$. These results indicate that spatial reference memory had been reduced in the nano-ZnO-treated group.

\section{Reacquisition performance}

The reacquisition phase was applied 24 hours after retention. The hidden platform was placed into the middle of the SW quadrant to assess an animal's ability to reacquire the learned strategy. During the reacquisition phase, significantly shorter escape latencies were obtained on the training trial $(P<0.05$, repeated-measures ANOVA), at the second trial (control, $6.51 \pm 1.50$ seconds; nano-ZnOtreated group, $24.56 \pm 5.93$ seconds, $P<0.01)$, the third trial (control, $4.86 \pm 0.77$ seconds; nano-ZnO-treated

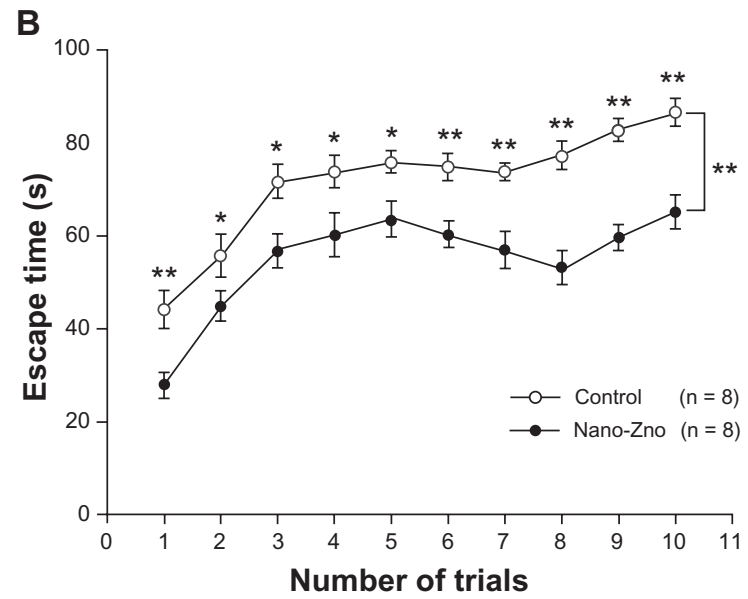

Figure 2 (A) Comparison of escape latency of acquisition phase between nano-ZnO-treated group and control group. (B) Comparison of percentage of escape latency in southwest quadrant between nano-ZnO-treated group and control group.

Notes: Data are expressed as mean \pm standard error of the mean; $* P<0.05$ compared with control group; $* * P<0.01$ compared with control group. Abbreviation: nano- $\mathrm{ZnO}$, zinc oxide nanoparticles. 
A

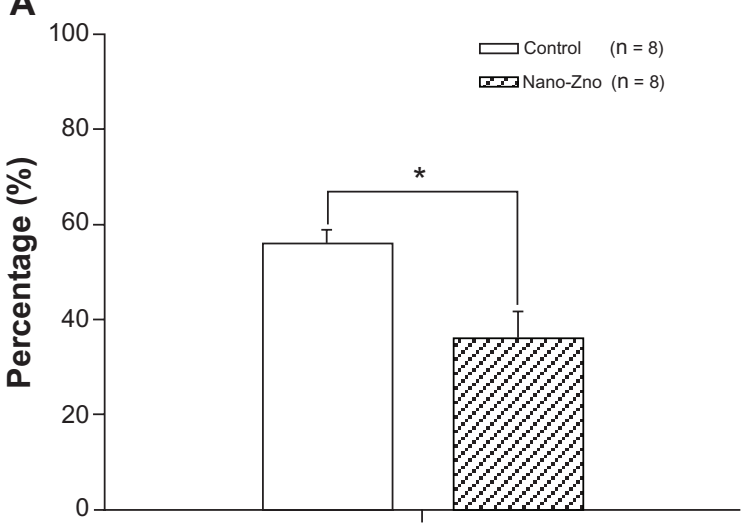

B

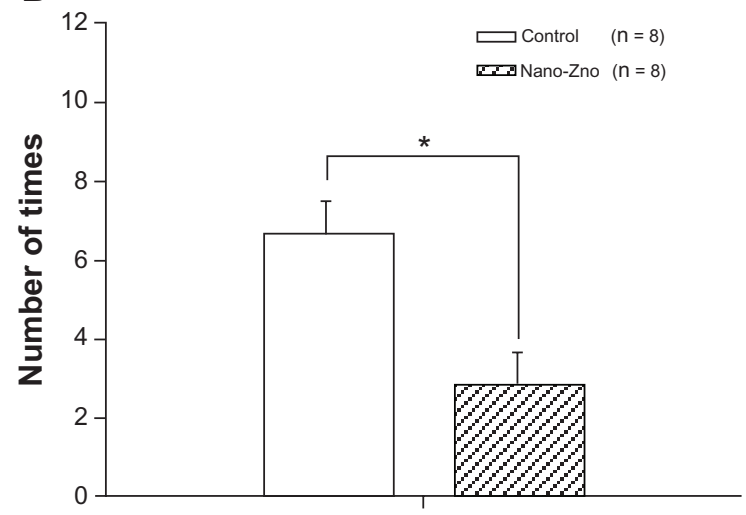

Figure 3 (A) Comparison of temporal distribution of southeast quadrant in probe trial between nano-ZnO-treated group and control group. (B) Comparison of number of times crossing hidden platform in probe trial between nano-ZnO-treated group and control group.

Notes: Data are expressed as mean \pm standard error of the mean; $* P<0.05$ compared with control group.

Abbreviation: nano- $\mathrm{ZnO}$, zinc oxide nanoparticles.

group, $8.94 \pm 1.90$ seconds, $P<0.05$ ), and the fourth trial (control, $1.61 \pm 0.23$ seconds; nano-ZnO-treated group, $5.04 \pm 1.03$ seconds, $P<0.05$ ) (Figure 4). Interestingly, at the same time, in temporal distribution of the quadrants, rats of the nano-ZnO-treated group spent a dramatically longer time in the SW quadrant (original location quadrant) in which the hidden platform had been located in the acquisition phase (control, $8.91 \% \pm 2.07 \%$; nano-ZnO-treated group, $14.82 \% \pm 2.85 \%, P<0.05$, repeated-measures ANOVA), and shorter time in the NE quadrant (novel location quadrant), in which the hidden platform was relocated in the reacquisition phase (control, $61.10 \% \pm 4.06 \%$; nano-ZnO-treated group, $42.75 \% \pm 3.59 \%, P<0.01$, repeated-measures ANOVA) than the control group (Figure 5). There was no

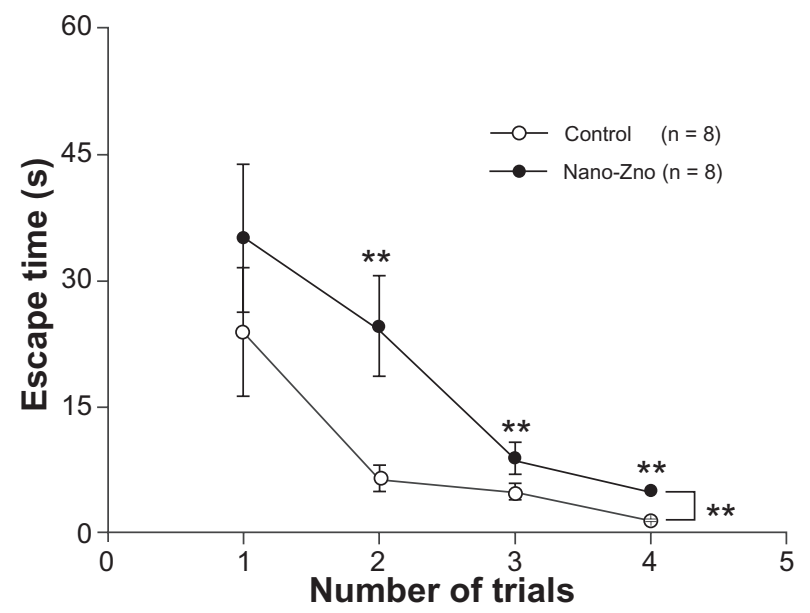

Figure 4 Comparison of escape latency of reacquision phase between nano- $\mathrm{ZnO}$ treated group and control group.

Notes: Data are expressed as mean \pm standard error of the mean; $* P<0.05$ compared with control group; **P $<0.01$ compared with control group. Abbreviation: nano- $\mathrm{ZnO}$, zinc oxide nanoparticles. significant difference between the two groups in the NW quadrant (control, $13.72 \% \pm 1.92 \%$; nano-ZnO-treated group, $19.87 \% \pm 1.97 \%, P>0.05$, repeated-measures ANOVA) and SE quadrant (control, $15.19 \% \pm 2.36 \%$; nano-ZnO-treated group, $20.05 \% \pm 2.59 \%, P>0.05$, repeated-measures ANOVA). Therefore, reacquisition of spatial information was slowed down in rats of the nano- $\mathrm{ZnO}$ group due to much more time spent on exploration in the original location quadrant.

\section{LTP and depotentiation}

One of our foremost aims with this study was to investigate the alteration of facilitation of synaptic plasticity of the DG in the nano-ZnO-treated group. The data were found to be incompatible with the performance in the MWM. The nano$\mathrm{ZnO}$-treated group resulted in a higher fEPSP slope but had worse MWM performance than the control group. As observed in the DG region, application of TBS resulted in an LTP with fEPSP slope value of $126.47 \% \pm 0.89 \%$ (control); $168.16 \% \pm 0.64 \%$ (nano-ZnO-treated group) $(P<0.01$, repeated-measures ANOVA, Figure 6A). Data showed higher fEPSP slope in the nano- $\mathrm{ZnO}$ group.

To examine whether nano- $\mathrm{ZnO}$ was involved in depotentiation, an LFS induction protocol ( $600 \times 2$ stimuli, 20 minutes $)$ was employed, and elicited significant depotentiation both in nano- $\mathrm{ZnO}$ and control group. Application of LFS resulted in a depotentiation with fEPSP slope value of $84.71 \% \pm 4.95 \%$ (control) and $124.24 \% \pm 6.00 \%$ (nano-ZnO-treated group, $P<0.01$ ), even lower than $100.29 \% \pm 2.00 \%$ (baseline, $P<0.05$, repeated-measures ANOVA, Figure 6A). Since fEPSP slopes showed significant differences between nano$\mathrm{ZnO}$ and control groups before LFS, the differences in these after LFS could not be used to estimate the effect of nano- $\mathrm{ZnO}$ 

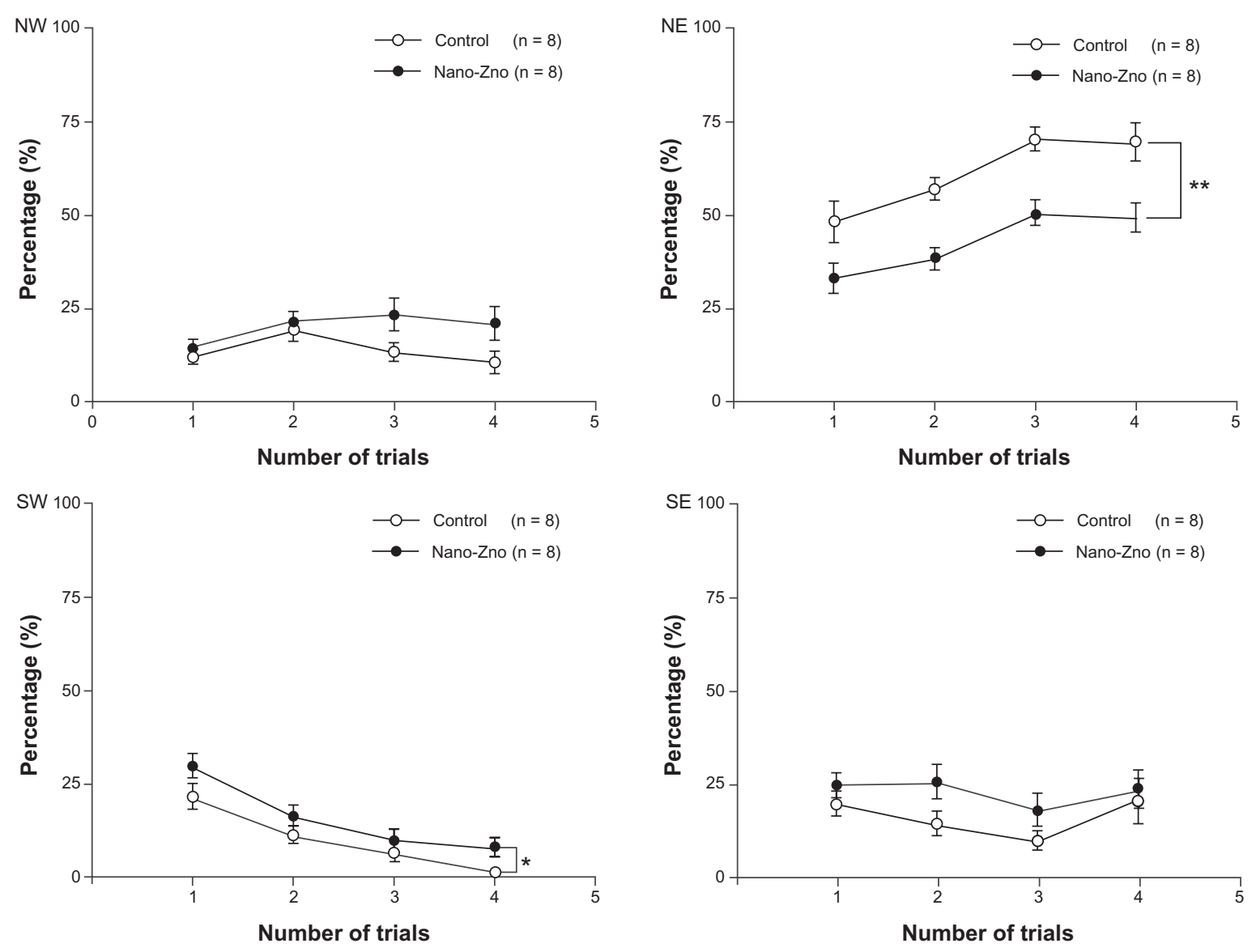

Figure 5 Comparison of percentages of escape latency in NW, NE, SW, and SE quadrant between nano-ZnO-treated group and control group in reacquision phase. Statistical significances were obtained in quadrant SW and NE.

Notes: Data are expressed as mean \pm standard error of the mean; $* P<0.05 ; * * P<0.01$ compared with control group.

Abbreviations: nano-ZnO, zinc oxide nanoparticles; NE, northeast; NW, northwest; SE, southeast; SW, southwest.

on depotentiation. Since the significant differences existed between nano- $\mathrm{ZnO}$ and control groups before the LFS, the significant differences after the LFS between nano- $\mathrm{ZnO}$ and control groups can not be used to illustrate whether there was an effect on synaptic plasticity by nano-ZnO. Therefore, LTP-evoked responses of the last 20 minutes were normalized and used for the baseline of depotentiation (1 per minute). Data showed that the value of fEPSP slope was $76.9 \% \pm$ $0.52 \%$ (control) and $70.6 \% \pm 0.23 \%$ (nano-ZnO-treated group, $P>0.05$, repeated-measures ANOVA, Figure 6B).

\section{Discussion}

Zinc is known to adversely affect the central nervous system of children during fetal development. The nervous system seems to be extremely susceptible to the ion both in physiological and pathological conditions. ${ }^{26}$ Most of the previous studies using animals showed behavioral and spatial learning effects related to zinc exposure. The present results indicate that zinc modulated hippocampal plasticity with bidirectional effects. The lower concentrations of zinc inhibited depotentiation but not LTP. Such a switch-like effect of zinc was attributed to zinc acting via N-methyl-D-aspartate (NMDA) receptors. NR1/NR2A and NR1/NR2B NMDA receptors play complex roles in synaptic plasticity. ${ }^{27}$ Furthermore, zinc modulates a wide variety of ion channels, and alternative ways in which zinc might act at synapses have been delineated. ${ }^{28}$ In the present study, we focused on the nano-ZnO exposure during the postnatal brain growth spurt in rodents, when the nervous system might be most vulnerable.

\section{Effects of nano-ZnO on acquisition and retention phase in MWM}

After 8-weeks treatment, nano-ZnO-treated rats began to exhibit cognitive deficits. The prolonged escape latencies in the acquisition phase indicated a slowing down of learning in nano-ZnO-treated rats. Importantly, a decreased percentage in escape latency of temporal distribution in the target (SW) quadrant showed a "misleading" status in nano-ZnO-treated rats. Because of the poor performance of spatial reference learning, rats had to search for the hidden platform around 

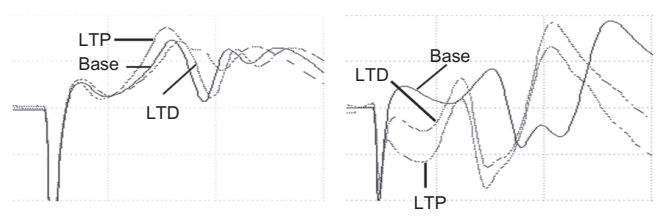

A

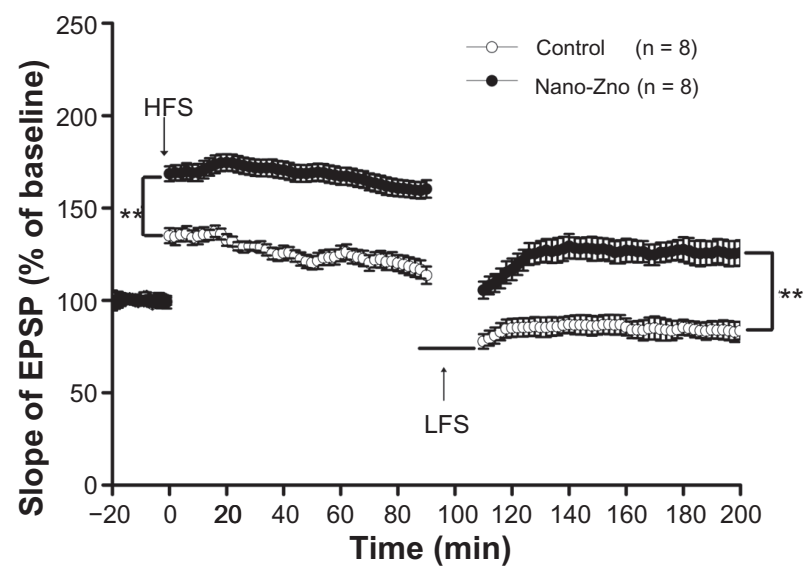

B

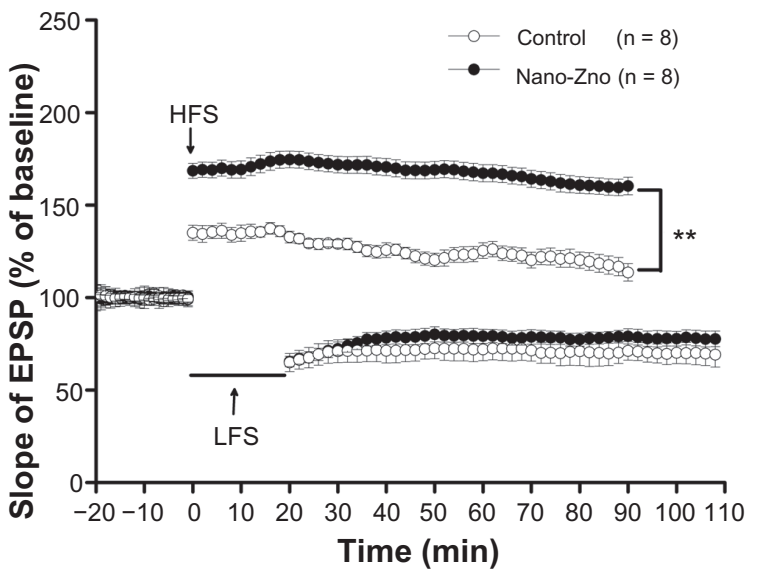

Figure 6 Electrophysiological data. LTP was induced using TBS, and depotentiation was induced using LFS after recording a stable baseline for 20 minutes. LTP lasted at least 90 minutes. (A) Comparison of slopes of EPSP of LTP and depotentiation in nano-ZnO-treated group and control group. (B) Last 20 minutes of LTP-evoked responses was normalized and used for the baseline responses of depotentiation. Comparison of slopes of EPSP of LTP and depotentiation in nano-ZnO-treated group and control groups. Notes: Data are expressed as mean \pm standard error of the mean; ** $P<0.01$ compared with control group.

Abbreviations: EPSP, excitatory postsynaptic potential; HFS, high frequency stimulation; LFS, low frequency stimulation; LTD, long-term depotentiation; LTP, long-term potentiation; nano- $\mathrm{ZnO}$, zinc oxide nanoparticles; TBS, theta burst stimulation.

the whole pool, which led them to spend more time in the non-target quadrant. Eventually, deficit learning and hinder orientation contributed to the prolonged escape latencies and resulted in a worse performance in temporal distribution of the target quadrant and the number of crossings of the hidden platform in the retention phase.

\section{Effects of nano- $\mathrm{ZnO}$ on reacquisition phase in MWM}

In this phase, the hidden platform had been moved from the SW quadrant to the NE quadrant. Learning and memory of the new platform location was examined to assess the animals' abilities to reacquire the learned strategy when the platform was moved to a new location (reversal). ${ }^{29}$ Rats in the nano$\mathrm{ZnO}$-treated group spent more time finding the hidden platform. It is worth noting that nano-ZnO-treated rats spent less time in the new quadrant (NE) and spent more time in the original quadrant (SW) than the control group in temporal distribution. Furthermore, the lack of significant differences in the NW and SE quadrants between rats of the control group and the nano-ZnO-treated group, in which the platform was never placed during the MWM, showed that rats of the nano$\mathrm{ZnO}$-treated group took a longer period of time to find the new location of the hidden platform due to searching in the original location quadrant. This suggests a strong memory delayed the escape latency in the reacquisition phase, rather than a poor memory. A previous study reported that in wild-type mice, performance in the reversal MWM task was attributed to the capacity for cognitive flexibility; that is, the ability to simultaneously inhibit a previously acquired spatial navigation strategy and develop a new strategy. ${ }^{30}$ In the present study, this capacity was weakened in rats of the nano-ZnO-treated group. Nano-ZnO-treated rats pertinaciously insisted on an inflexible strategy, suggesting that the memory associated with the original learning of the task stably remained in the nano-ZnO-treated rats. These rats lacked flexibility of learning and memory compared with that of control group.

\section{Effects of nano-ZnO on LTP and depotentiation}

Underlying mechanisms of learning and memory induction and maintenance have been associated with LTP and depotentiation. Hence, our work focused on these effects of nano-ZnO.

Previous studies have shown that zinc perfusion attenuated mossy fiber LTP in vitro, ${ }^{31}$ whereas Izumi et $\mathrm{al}^{27}$ claimed no effect of zinc in micromolar concentrations on LTP in area CA1 slices. Our results show the opposite: nano-ZnO significantly enhanced LTP, then hardly impacted depotentiation. However, the rapid, automatic aspect of context-specific event 
encoding is not only dependent on intact synaptic plasticity but also intact function of the hippocampus..$^{32}$ Although LTP in the hippocampus is well known to underlie learning and memory, LTD in the hippocampus is regarded as a crucial mechanism related to the acquisition of a comprehensive spatial map..$^{33}$ The landmark encoding, conveying information about orientation in space, could be mediated by weakened spatial information in the dentate gyrus. ${ }^{34}$ Thus, based on the latter investigations, it is hard to say that an augmented LTP enhanced by nano- $\mathrm{ZnO}$ could improve the ability of learning and memory in rats.

From the perspective of neuroelectrophysiology and molecular biology, long-term synaptic plasticity (including LTP and depotentiation) is an endowed capability that regulates efficiency of synaptic transmission via adjustment of the number of NMDA receptors and a switch of NMDA receptor subtypes. Such unequal effects of nano-ZnO on synaptic plasticity in the DG region resulted in over-amplification with relative and/or absolute less decay of spatial information. This supports the interpretation of the finding that the spatial information reacquisition process of nano-ZnOtreated rats was delayed in MWM. In the acquisition phase, acquired spatial information was excessively enhanced by LTP and deficiently weakened by depotentiation, resulting in prolonged escape latencies in the reacquisition phase. It may also be the reason why the nano- $\mathrm{ZnO}$-treated rats spent more time exploring the original rather than the novel location quadrant to find the platform. Furthermore, it is noteworthy that the intensity of spatial information was weakened by LFS and lower than baseline in the control group, while the intensity was higher than that of baseline in the nano-ZnOtreated group. This implies that the intensity of the neural signal was enhanced even after depotentiation in the nanoZnO-treated group.

We conclude that hyperactive LTP and insufficient depotentiation affected the process of spatial information, and resulted in the difficulties of finding the replaced hidden platform. The imbalance between LTP and depotentiation delayed the learning progress in the reacquisition phase in the nano-ZnO-treated group. Nano-ZnO-treated rats appear to depend on memory of the original information rather than using maze external clues (novel information) to guide space exploration when the novel spatial information did not match with memory. In other words, strategy flexibility was more rigid in the nano- $\mathrm{ZnO}$-treated group than in the control.

The effects of zinc on synaptic plasticity have been extensively studied. Most previous studies suggested zinc attenuated LTP in mossy fibers, ${ }^{35}$ but another study showed
LTP was enhanced by zinc in the hippocampal CA1 region. ${ }^{36}$ Recently, Izumi et al found zinc induction of LTP at low micromolar concentrations, while attenuating it at high micromolar concentrations. Homeostasis of synaptic zinc is critical for LTP induction. ${ }^{37}$ In the present study, long-term exposure to nano- $\mathrm{ZnO}$ may have disrupted the homeostasis of synaptic zinc, which would then lead to hyperactive LTP and insufficient depotentiation.

In summary, this study demonstrated that daily intraperitoneal injections of nano- $\mathrm{ZnO}$ given over a period of 8 weeks to young Wistar rats affected brain function by enhancing LTP while barely influencing depotentiation in the DG region of the hippocampus. This bidirectional effect on long-term synaptic plasticity broke the balance between stability and flexibility of cognition. This can explain the phenomenon that nano-ZnO-treated rats displayed high LTP but a crude performance of the MWM. These results are consistent with the hypothesis that LTP and depotentiation are not independent but an entity in modulating efficiency of spatial cognition.

\section{Acknowledgments}

This work was partly supported by the National Natural Science Foundation of China (31070890) and The UK Royal Academy of Engineering on a Major Research Exchanges Award (Ref 5502).

\section{Disclosure}

The authors report no conflicts of interest in this work.

\section{References}

1. Poletto FS, Silveira RP, Fiel LA, et al. Size-control of poly (epsiloncaprolactone) nanospheres by the interface effect of ethanol on the primary emulsion droplets. J Nanosci Nanotechnol. 2009;9:4933-4941.

2. Sohn Y, Pradhan D, Radi A, Leung KT. Interfacial electronic structure of gold nanoparticles on $\mathrm{Si}(100)$ : alloying versus quantum size effects. Langmuir. 2009;18(25):9557-9563.

3. Asl SK, Sadrnezhaad SK, Rad MK. The seeding effect on the microstructure and photocatalytic properties of $\mathrm{ZnO}$ nano powders. Mater Lett. 2010;18:1935-1938.

4. Maczka M, Macalik L, Hermanowicz K, Kepinski L, Tomaszewski P. Phonon properties of nanosized bismuth layered ferroelectric material $\mathrm{Bi}_{2} \mathrm{WO}_{6}$. J Raman Spectrosc. 2010;41:1059-1066.

5. Zvyagin AV, Zhao X, Gierden A, Sanchez W, Ross JA, Roberts MS. Imaging of zinc oxide nanoparticle penetration in human skin in vitro and in vivo. J Biomed Opt. 2008;13:064031.

6. Sharma V, Shukla RK, Saxena N, Parmar D, Das M, Dhawan A. DNA damaging potential of zinc oxide nanoparticles in human epidermal cells. Toxicol Lett. 2009;185:211-218.

7. Wang B, Feng W, Wang M, et al. Acute toxicological impact of nano- and submicro-scaled zinc oxidepowder on healthy adult mice. $J$ Nanopart Res. 2008;10:263-276.

8. Hanley C, Layne J, Punnoose A, et al. Preferential killing of cancer cells and activated human $\mathrm{T}$ cells using $\mathrm{ZnO}$ nanoparticles. Nanotechnology. 2008;19:295103. 
9. Jeng HA, Swanson J. Toxicity of metal oxide nanoparticles in mammalian cells. J Environ Sci Health A Tox Hazard Subst Environ Eng. 2006;41:2699-2711.

10. Lai JC, Lai MB, Jandhyam S, et al. Exposure to titanium dioxide and other metallic oxide nanoparticles induces cytotoxicity on human neural cells and fibroblasts. Int J Nanomedicine. 2008;3:533-545.

11. Remillard CV, Yuan JX-J. Activation of $\mathrm{K}^{+}$channels: an essential pathway in programmed cell death. Am J Physiol Lung Cell Mol Physiol. 2004;286:L49-L67.

12. Zhao J, Xu L, Zhang T, Ren G, Yang Z. Influences of nanoparticle zinc oxide on acutely isolated rat hippocampal CA3 pyramidal neurons. Neurotoxicology. 2009;30:220-230.

13. Deng X, Luan Q, Chen W, et al. Nanosized zinc oxide particles induce neural stem cell apoptosis. Nanotechnology. 2009;20:115101.

14. Sayes CM, Reed KL, Warheit DB. Assessing toxicity of fine and nanoparticles: comparing in vitro measurements to in vivo pulmonary toxicity profiles. Toxicol Sci. 2007;97(1):163-180.

15. Sousa F, Mandal S, Garrovo C, et al. Functionalized gold nanoparticles: a detailed in vivo multimodal microscopic brain distribution study. Nanoscale. 2010;2:2826-2834.

16. Kozik MB, Maziarz L, Godlewski A. Morphological and histochemical changes occurring in the brain of rats fed large doses of zinc oxide. Folia Histochem Cytochem (Krakow). 1980;18:201-206.

17. Seil JT, Webster TJ. Decreased astroglial cell adhesion and proliferation on zinc oxide nanoparticle polyurethane composites. Int $J$ Nanomedicine. 2008;3:523-531.

18. Morris R. Developments of a water-maze procedure for studying spatial learning in the rat. J Neurosci Methods. 1984;11:47-60.

19. Quan MN, Tian YT, Xu KH, Zhang T, Yang Z. Post weaning social isolation influences spatial cognition, prefrontal cortical synaptic plasticity and hippocampal potassium ion channels in Wistar rats. Neuroscience. 2010;169(1):214-222.

20. Shuman T, Wood SC, Anagnostaras SG. Modafinil and memory: effects of modafinil on Morris water maze learning and Pavlovian fear conditioning. Behav Neurosci. 2009;123:257-266.

21. Söderström I, Strand M, Ingridsson AC, Nasic S, Olsson T. 17betaestradiol and enriched environment accelerate cognitive recovery after focal brain ischemia. Euro J Neurosci. 2009;29:1215-1224.

22. Paxinos G, Watson C. The Rat Brain in Stereotaxic Coordinates. San Diego: Academic Press; 1986.

23. Boric K, Muñoz P, Gallagher M, Kirkwood A. Potential adaptive function for altered long-term potentiation mechanisms in aging hippocampus. $J$ Neurosci. 2008;28:8034-8039.

24. Lopes Aguilar C, Romcy-Pereira RN, Escorsim Szawka R, Galvis-Alonso OY, Anselmo-Franci JA, Pereira Leite J. Muscarinic acetylcholine neurotransmission enhances the late-phase of long-term potentiation in the hippocampal-prefrontal cortex pathway of rats in vivo: a possible involvement of monoaminergic systems. Neuroscience. 2008;153:1309-1319.
25. Ishida T, Sato T, Irifune M, Tanaka K, Nakamura N, Nishikawa T. Effect of acetaminophen, a cyclooxygenase inhibitor, on Morris water maze task performance in mice. $J$ Psychopharmacol. 2007;21: 757-767.

26. Fan G, Feng C, Li Y, et al. Selection of nutrients for prevention or amelioration of lead-induced learning and memory impairment in rats. Ann Occup Hyg. 2009;53:341-351.

27. Izumi Y, Auberson YP, Zorumski CF. Zinc modulates bidirectional hippocampalplasticity by effects on NMDA receptors. $J$ Neurosci. 2006;26:7181-7188.

28. Kay AR, Tóth K. 2006. Is zinc a neuromodulator? Sci Signal. 2008;1(19):re3.

29. Kerr AL, Hensel ML, Peterson TC, Villatoro LO, Nye SH, Swain RA. Introgression of brown norway chromosome 13 improves visual spatial memory in the Dahl S rat. Behav Genet. 2009;40:76-84.

30. Labrie V, Duffy S, Wang W, Barger SW, Baker GB, Roder JC. Genetic inactivation of D-amino acid oxidase enhances extinction and reversal learning in mice. Learn Mem. 2009;16:28-37.

31. Takeda A, Ando M, Kanno S, Oku N. Unique response of zinc in the hippocampus to behavioral stress and attenuation of subsequent mossy fiber long-term potentiation. Neurotoxicology. 2009;30: 712-717.

32. Morris RG. Elements of a neurobiological theory of hippocampal function: the role of synaptic plasticity, synaptic tagging and schemas. Eur J Neurosci. 2006;23:2829-2846.

33. Kemp A, Manahan-Vaughan D. Hippocampal long-term depression: master or minion in declarative memory processes? Trends Neurosci. 2007;30:111-118.

34. Witter MP, Moser EI. Spatial representation and the architecture of the entorhinal cortex. Trends Neurosci. 2006;29:671-678.

35. Ando M, Oku N, Takeda A. Zinc-mediated attenuation of hippocampal mossy fiber long-term potentiation induced by forskolin. Neurochem Int. 2010;57:608-614.

36. Lorca RA, Rozas C, Loyola S, et al. Zinc enhances long-term potentiation through $\mathrm{P} 2 \mathrm{X}$ receptor modulation in the hippocampal CA1 region. Eur J Neurosci. 2011;33(7):1175-1185.

37. Takeda A, Suzuki M, Tamano H, Ando M, Oku N. Differential effects of zinc influx via AMPA/kainate receptor activation on subsequent induction of hippocampal CA1 LTP components. Brain Res. 2010;1354:188-195.
International Journal of Nanomedicine

\section{Publish your work in this journal}

The International Journal of Nanomedicine is an international, peerreviewed journal focusing on the application of nanotechnology in diagnostics, therapeutics, and drug delivery systems throughout the biomedical field. This journal is indexed on PubMed Central, MedLine, CAS, SciSearch ${ }^{\circledR}$, Current Contents ${ }^{\circledR} /$ Clinical Medicine,

\section{Dovepress}

Journal Citation Reports/Science Edition, EMBase, Scopus and the Elsevier Bibliographic databases. The manuscript management system is completely online and includes a very quick and fair peer-review system, which is all easy to use. Visit http://www.dovepress.com/ testimonials.php to read real quotes from published authors. 